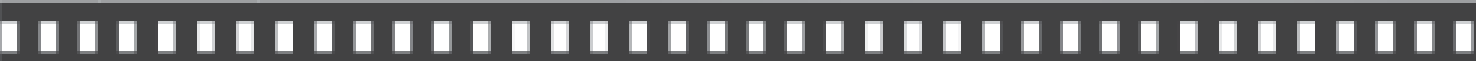

\author{
Decifrando a linguagem da caixa-preta: \\ Vilém Flusser e a Análise do Discurso
}

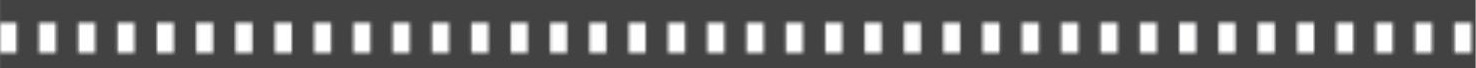

Paula Mousinho Martins
Teófilo Augusto da Silva

Artigo recebido em: 28/01/2013

Artigo aprovado em: 25/06/2013

DOI 10.5433/1984-7939.2013v9n15p171 


\title{
Decifrando a linguagem da caixa-preta: Vilém Flusser e a Análise do Discurso
}

Decoding the language of the black box: Vilém Flusser and Discourse Analysis

\author{
Paula Mousinho Martins* \\ Téfilo Augusto da Silva **
}

\begin{abstract}
Resumo: $O$ artigo analisa o livro Filosofia da caixa preta: ensaios para uma futura filosofia da fotografia, de Vilém Flusser, e de que forma este pode ser aproximado da vertente francesa do movimento denominado Análise do Discurso. A possibilidade dessa aproximação encontra respaldo no próprio pensamento de Flusser, na medida em que este considera o discurso e o diálogo "fases do processo de comunicação fotográfica enquanto manipulação de informações”. (FLUSSER, 2002, p.46).

Palavras-chave: Vilém Flusser. Fotografia. Linguagem. Análise do Discurso $(A D)$.

Abstract: The article analyses the book Philosophy of the black box: essays on a future philosophy of photography by Vilém Flusser, and how it can be approximated to the French strand of the movement called Discourse Analysis. The possibility of this approach is supported by the very thought of Flusser, in that it considers the discourse and dialogue "phase of the communication process while photographic manipulation of information”. (FLUSSER, 2002, p.46).
\end{abstract}

Keywords: Vilém Flusser. Photography. Language. Discourse Analysis (DA).

\footnotetext{
* Graduada em História pela Pontifícia Universidade Católica do Rio de Janeiro (PUC/RJ). Mestre em Filosofia pela Pontifícia Universidade Católica do Rio de Janeiro (PUC/RJ). Doutora em Filosofia pela Universidade Federal do Rio de Janeiro (UFRJ). Professora associada da Universidade Estadual do Norte Fluminense Darcy Ribeiro (UENF). Experiência na área de filosofia, atuando nos seguintes temas: fenomenologia, filosofia da mente, hermenêutica e linguagem. E-mail: pmartins@uenf.br

** Bacharel em Comunicação Social - Publicidade e Propaganda pela Universidade Federal do Espírito Santo (UFES). Especialista em Artes Visuaispelo Senac do Rio de Janeiro. Mestre em Cognição e Linguagem pela Universidade Estadual do Norte Fluminense Darcy Ribeiro (UENF). Coordenador do curso de Artes Visuais da Faculdade de Filosofia de Campos (Uniflu). Editor júnior da revista Agenda Social. Membro fundador e primeiro presidente do Fotoclube Goytacazes. Email: teo.professor@gmail.com
} 


\section{Introdução}

O presente artigo tem como foco principal o livro Filosofia da caixa preta: ensaios para uma futura filosofia da fotografia, de Vilém Flusser - autor tcheco que residiu por trinta e quatro anos no Brasil (19301964) e dedicou grande parte de sua vida ao estudo dos meios da comunicação e da cultura no século XX. Nesta pequena coletânea de ensaios ${ }^{1}$, o pensador autodidata elabora uma peculiar teoria do fenômeno fotográfico na qual também é desenvolvida uma desafiadora análise da sociedade "pós-histórica" ou "pós-industrial" - aquela onde a onipresença das imagens mediadas por tecnologias veio substituir o predomínio dos textos e dos conceitos próprios à sociedade industrial.

Flusser $(2002$, p.28, 67) define o mundo pós-histórico a partir do conceito de aparelho, visando caracterizar com isso uma sociedade da qual o trabalho não é mais um dos alicerces: diferentemente dos "instrumentos" da era industrial, os "aparelhos" pós-industriais não laboram nem modificam o mundo. Ora, o aparelho fotográfico é o "patriarca de todos os aparelhos", o "protótipo", "o mais simples e relativamente o mais transparente de todos os aparelhos". Em sua aparência "inócua e primitiva", mesmo na versão analógica ou pré-digital, ele prefigura todos os aparelhos característicos da atualidade - desde o minúsculo chip de computador até as grandes superestruturas administrativas da sociedade. (FLUSSER, 2002, p.19). Filosofia da caixa preta (FCP) faz da análise da fotografia um meio de descrever, criticamente, as engrenagens "pósideológicas" do vasto aparelho industrial, publicitário, econômico e político que constitui o mundo contemporâneo. $\mathrm{O}$ fio condutor do livro é a denúncia

\footnotetext{
${ }^{1}$ Filosofia da caixa preta resume, como se sabe, conferências pronunciadas na França e na Alemanha que, a pedido da European Photography, foram reunidas no livro publicado primeiramente em alemão no ano de 1983.

${ }^{2} \mathrm{O}$ conceito de ideologia só tem sentido no contexto de uma sociedade industrial (capitalista ou socialista), mas, como veremos, não é apropriado ao mundo pós-industrial, tampouco ao conceito de aparelho. Para este mundo pós-histórico, aliás, "ainda não dispomos de categorias adequadas". (FLUSSER, 2002, p.22). Nesta perspectiva, "perguntas industriais (por exemplo, as marxistas) não são mais competentes para aparelhos". (FLUSSER, 2002, p.22). Isto vale evidentemente também para o conceito de ideologia, central para a teoria marxista.
} 
do caráter totalitário e eminentemente mistificador da cultura superficial (embora altamente abstrata e codificada) das imagens técnicas.

Produto híbrido da junção de um paradigma cartesiano (calculável, atomista, "claro e distinto" etc.) com uma estrutura quântica ("pequenos saltos aleatórios"), o grande mosaico multicolorido em que se transformou o mundo nos dias de hoje, em contraste com a realidade cinzenta do século XIX 3 , tem, escreve Flusser (2002, p.62), "o poder de programar magicamente o comportamento humano". Vive-se, age-se, conhece-se e valoriza-se sob a influência subliminar dessa gigantesca engrenagem imagético-simbólica "que manipula e robotiza a vida em todos os seus aspectos, desde os gestos exteriorizados ao mais íntimo dos pensamentos, desejos e sentimentos". (FLUSSER, 2002, p.67). Decifrar o significado do fenômeno fotográfico faz parte, pois, de um projeto maior de emancipação do homem contemporâneo, cujo objetivo é libertá-lo da alienação imposta pelo "programa do aparelho" a fim de alcançar a liberdade criativa de um verdadeiro fotógrafo.

Em que pese a originalidade de seus pontos de vista ${ }^{4}$, a abordagem crítica de FCP caminha ao encontro da grande onda estruturalista que dominou as análises semióticas da fotografia no século XX. Tais análises insurgem-se, como se sabe, contra o discurso da "mimese" e da "transparência" ao conceberem a fotografia como algo codificado sob os mais diversos aspectos (técnico, cultural, sociológico, estético etc.) $)^{5}$. O que desejamos mostrar na parte final deste artigo é de que modo, para além da convergência com os vários vieses do estruturalismo, as análises de FCP também podem ser aproximadas da vertente francesa do movimento denominado Análise do Discurso (AD), daí obtendo-se uma ampliação crítica das suas quatro categorias básicas - aparelho, programa,

\footnotetext{
3 "No século XIX, o mundo lá fora era cinzento: muros, jornais, livros, roupas, instrumentos, tudo isso oscilava entre o branco e o preto, dando em seu conjunto a impressão do cinza: impressão de textos, teorias, dinheiro. Atualmente tudo isso grita alto em todas as tonalidades do arco-íris." (FLUSSER, 2002, p.62).

${ }^{4}$ FCP não faz menção a qualquer teoria e sequer possui um índice bibliográfico.

${ }^{5}$ Pensamos principalmente em Umberto Eco (2002); Roland Barthes (1984) e o próprio grupo $\mu$ (Jacques Dubois, Philippe Dubois, Francis Edeline, Jean-Marie Klinkenberg e Philipe Minguet). (DUBOIS, 2000, p.37).
} 
imagem e informação. Acreditamos que essa aproximação encontra respaldo no próprio pensamento de Flusser, visto que este trata o discurso e o diálogo como "fases do processo de comunicação fotográfica enquanto manipulação de informações”. (FLUSSER, 2002, p.46).

Desde seu surgimento, na década de 1960, a AD tem se preocupado com a análise de textos publicitários ou jornalísticos, mas, no que tange à fotografia são raras as suas incursões. Ao relacionar alguns preceitos desta disciplina da linguística, principalmente de autoria de Dominique Maingueneau, ao pensamento de Flusser, pretenderemos enfatizar a visão da imagem fotográfica como instrumento discursivo de poder, manipulação e controle social.

\section{Aparelhos, funcionários e fotógrafos}

Quanto mais houver gente fotografando, tanto mais difícil se tornará o deciframento de fotografias, já que todos acreditam saber fazê-las. (FLUSSER, 2002, p.79).

Vive-se o apogeu da massificação fotográfica, mas, quanto mais cresce a disposição da população mundial para fotografar, mais diminui o entendimento do significado deste ato. Grande parte da humanidade sabe perfeitamente apertar botões e realizar enquadramentos, mas isto não transforma ninguém em bom leitor de imagens fotográficas. $\mathrm{O}$ ato de fotografar não é como o ato de escrever, que nos obriga a também saber ler. A compreensão do real estatuto da fotografia revela-se de fato difícil para o observador ingênuo, incapaz de reconhecer que imagens fotográficas são conceitos transcodificados que apenas pretendem ser "impressões automáticas" do mundo. "É tal pretensão que deve ser decifrada por quem quiser receber a verdadeira mensagem da fotografia." (FLUSSER, 2002, p.40).

Esse deciframento exige, antes de tudo, atentar para o que se passa no momento mesmo do "gesto" fotográfico, isto é, no movimento que une 
as intenções codificadoras - ora convergentes, ora divergentes - do fotógrafo e do aparelho ${ }^{6}$.

A fotografia é, pois, mensagem que articula ambas as intenções codificadoras. Enquanto não existir crítica fotográfica que revele essa ambiguidade do código fotográfico, a intenção do aparelho prevalecerá sobre a intenção humana. (FLUSSER, 2002, p.43).

Com efeito, se é verdade que pelo controle do input e do output o fotógrafo parece dominar o aparelho, por ignorar os processos interiores ao programa, todavia, é o fotógrafo quem na verdade é dominado. Fotografar nada mais é que permutar símbolos já contidos no programa interno à "caixa preta", ou seja, uma atividade mecânica, repetitiva e burocratizada. A ideia flusseriana do funcionário que apenas aperta botões de aparelhos já montados e programados encontra eco no pensamento de Hannah Arendt, como aponta a análise de Gustavo Bernardo (apud MENEZES 2010, p.176):

Hannah Arendt, ao estudar a banalidade do mal, se perguntou como gente insignificante foi transformada pelo aparelho nazista em funcionários poderosos. Flusser tentou olhar o outro lado do problema: gente responsável e culta sendo transformada em funcionários insignificantes que promovem, sem o perceber, males gigantescos, adequados aos aparelhos agigantados que os empregam.

Ora, o autêntico fotógrafo - e não o mero funcionário - não se deixa cercear por tais limites: "o fotógrafo manipula o aparelho, o apalpa, olha para dentro e através dele, a fim de descobrir sempre novas potencialidades", em outras palavras, ele "não está empenhado em modificar o mundo, mas em obrigar o aparelho a revelar suas

\footnotetext{
${ }^{6}$ Por trás da intenção do aparelho individual escondem-se intenções de inúmeros outros aparelhos: o aparelho da indústria fotográfica, que é formado pelo aparelho do parque industrial, que é produto do aparelho socioeconômico, etc. etc, - constituindo uma grande hierarquia de "intenções" cujo fito é programar a sociedade "para um comportamento propício ao constante aperfeiçoamento dos próprios aparelhos". (FLUSSER, 2002, p.42).
} 
potencialidades". (FLUSSER, 2002, p.42). O verdadeiro fotógrafo age, nesse sentido, "como um caçador que não se movimenta em pradaria aberta, mas na floresta densa da cultura". Esta selva consiste de "objetos culturais intencionalmente produzidos que vedam ao fotógrafo a visão da caça". (FLUSSER, 2002, p.29). Decifrar fotografias significa, assim, decifrar as "condições culturais dribladas pelo fotógrafo". Essas condições não transparecem diretamente nas imagens fotográficas, mas apenas "através das categorias do aparelho, por intermédio das quais a condição [cultural] foi tomada". (FLUSSER, 2002, p.30). A liberdade do fotógrafo consiste justamente em "jogar contra o aparelho": é este "jogar contra" que caracteriza a prática dos "fotógrafos experimentais" quando conscientemente procuram forçar o aparelho a produzir uma imagem que não está em seu programa. (FLUSSER, 2002, p.107).

\section{O estatuto da imagem fotográfica}

O que torna a imagem fotográfica diferente do desenho ou da pintura realista, nos quais a habilidade manual e a acuidade visual do artista são suficientes para apreender mimeticamente o mundo exterior? Ou por outras: qual é a especificidade da fotografia enquanto registro documental? Antes de analisarmos o posicionamento de Flusser sobre esta questão, vale assinalar que o exame do valor documental da fotografia pode ser tratado por três abordagens epistemológicas distintas, minuciosamente discutidas por Philippe Dubois (2000) em $O$ ato fotográfico.

A primeira abordagem equipara a fotografia ao desenho e ao desenho realista, isto é, a uma reprodução mimética do real - um "espelho" do mundo ou um ícone no sentido de Peirce. O "efeito de realidade" ligado à imagem fotográfica é atribuído à semelhança entre ela e seu referente, já que a fotografia é um analogon da realidade. (DUBOIS, 2000, p.26-33). 
A segunda abordagem epistemológica denuncia essa suposta faculdade da imagem fotográfica de se fazer "cópia exata" do real, pois para ela toda imagem já é uma interpretação ou transformação do real, quer dizer, uma formação cultural, ideológica e codificada. A fotografia nada mais seria que um conjunto de códigos ou um símbolo nos termos peircianos, o que veda qualquer ilusionismo ou pretensão de neutralidade à imagem fotográfica: esta não "representa" o real empírico simplesmente porque o real não existe fora dos discursos (ou das imagens) que tratam dele.

Por fim, a terceira abordagem marca um retorno ao referente conquanto livre do ilusionismo mimético da primeira abordagem. É a tese defendida pelo próprio Dubois (2000), além de Roland Barthes (1984), Rosalind Kraus (2010) e outros. Ela afirma que a imagem fotográfica é inseparável de sua experiência referencial ou do ato que a funda: a fotografia é em primeiro lugar índice, só então podendo tornar-se "parecida" (ícone) e adquirir um "sentido" (símbolo). Há uma conexão física incontornável entre a imagem fotográfica e o referente que ela denota. Por ser uma impressão, a fotografia remete a um único referente determinado: aquele que a causou física e quimicamente, o objeto real que "estava ali" em um determinado momento de tempo. (DUBOIS, 2000, p.43-52). Barthes (1984) nomeia isto "noema do isto foi" .

O que Barthes e Dubois querem dizer é que a imagem fotográfica e o mundo se encontram no mesmo nível de realidade, unidos que estão por uma cadeia física ininterrupta de causa e efeito. Nesta perspectiva, uma "marca indiciária" é uma representação por contato ou contiguidade, onde o "traço" ou índice fotográfico não remete a conceitos - como os símbolos - e sim a objetos reais, particulares e absolutamente individuais. Decorre daí o "princípio de singularidade indiciária": o referente fotográfico é sempre único, não podendo jamais replicar-se ontológica ou existencialmente. Por extensão metonímica e de acordo com a lógica

\footnotetext{
7 "Ao contrário [das] imitações na Fotografia, jamais posso negar que a coisa esteve lá. [...] O nome do noema da Fotografia será então: 'Isto-foi', ou ainda: o Intratável.” (BARTHES, 1984, p.115).
} 
da contiguidade, essa unicidade referencial modulará a relação entre o signo (imagem fotográfica) e o objeto significado (o referente fotográfico), pois, se é verdade que uma fotografia é sempre indefinidamente multiplicável e serial, essa reprodutibilidade opera apenas entre os signos (as imagens), não interferindo na unicidade do objeto denotado. (DUBOIS, 2000, p.72). Desse princípio de contiguidade referencial derivam-se ainda as funções de atestação e designação da imagem fotográfica, que vêm sublinhar a força extensiva e a propensão à irradiação metonímica do princípio de contiguidade: o traço fotográfico não é apenas uma testemunha ontológica daquilo que mostra; ele o "aponta" ou "designa". "Como dizia Peirce: o índice nada afirma; ele só diz: ali.” (DUBOIS, 2000, p.76) .

Bem, é justamente para contrariar a interpretação indiciária e o poder "atestativo" ou "designativo" da imagem fotográfica que Vilém Flusser formula seu pensamento em FCP. Tratar a fotografia como índice é para ele um procedimento acima de tudo perigoso, que conduziu exatamente ao problema do mundo atual, "onde imagens técnicas se formaram para eliminar textos". (FLUSSER, 2002, p.14). Conceber a imagem fotográfica como índice, isto é, como uma mensagem sem código, é o mesmo que dizer que ela prescinde de deciframento, isto é, que é uma autêntica janela real para o mundo sem qualquer filtro codificador"na qual deve se confiar tanto quanto se confia nos próprios olhos". (FLUSSER, 2002, p.14).

Sendo assim, "a despeito da automaticidade da impressão físicoquímica do mundo sobre a superfície da imagem", ao contemplarmos imagens técnicas "não é o mundo, mas determinados conceitos relativos ao mundo que vemos". (FLUSSER, 2002, p.14-15). Fotografias são imagens técnicas que transcodificam conceitos em superfícies; decifrá-las

\footnotetext{
${ }^{8}$ Dubois aproxima, assim, a fotografia da classe de palavras que a linguística denomina dêiticos, a saber, pronomes e certos adjetivos demonstrativos (esse, aqueles, isto, aquilo) ou apresentativos (aqui está, ali está), ou ainda certos advérbios de lugar (aqui, lá) ou de tempo (agora, anteriormente). Trata-se de "signos lingüísticos que não têm seu sentido neles mesmos, mas cujo significado completo depende da situação de enunciação na qual são utilizados, cada uso desses signos atribuindolhes um referente a cada vez específico, portanto variável em cada caso". (DUBOIS, 2000, p.76).
} 
é descobrir o que tais conceitos significam. Embora aparentemente objetivas (não-simbólicas), fotografias permanecem imagens: "superfícies que transcodificam processos em cenas". "Como toda imagem, ela é também 'mágica' e seu observador tende a projetar essa magia sobre o mundo." (FLUSSER, 2002, p.15). Quem vê uma imagem técnica vê também seu significado, embora indiretamente.

Observe-se que Flusser caracteriza a história humana como uma incessante luta da escrita (consciência histórica) contra a imagem (consciência mágica). A história ocidental realizou-se como um longo processo de "desmagicização" da cultura em benefício da "conceituação". (FLUSSER, 2002, p.10). Esta última etapa corresponde ao advento da "textolatria", que é tão "alucinatória" quanto a "idolatria" dos povos primitivos, só que calcada sobre os "textos inimagináveis" das ciências exatas. Trata-se do mundo da atualidade, repleto de imagens técnicas produzidas por aparelhos que nada mais são que "texto científico aplicado". (FLUSSER, 2002, p.10).

Enquanto as imagens tradicionais (históricas) constituíam "abstrações de primeiro grau", a imagem técnica (pós-histórica) é uma "abstração de terceiro grau" que abstrai uma das dimensões da imagem tradicional para dar origem ao texto (que por sua vez seria uma "abstração de segundo grau”). Em seguida, a imagem técnica reconstitui essa dimensão abstraída a fim de dar origem novamente a uma imagem. Resumindo: enquanto "as imagens tradicionais imaginavam o mundo, as imagens técnicas imaginam textos que concebem imagens que imaginam o mundo". (FLUSSER, 2002, p.13). Tratando a imagem fotográfica como "representação de superfície", Flusser (2002, p.7) pretende, sobretudo, salientar sua capacidade abstrativa de desmaterializar coisas e corpos.

De sorte que é apenas aparentemente que o significado das imagens técnicas se imprime de forma automática (ou indiciária) sobre suas superfícies: a automaticidade das imagens técnicas éilusória porque imagens

\footnotetext{
${ }^{9}$ As imagens tradicionais (pintura, desenho etc.) abstraem duas dimensões do fenômeno concreto, a saber, duas das quatro dimensões do espaço-tempo.
} 
técnicas são tão simbólicas quanto qualquer outra imagem, devendo ser igualmente decifradas por quem deseja captar-lhes o significado. Tratase, contudo, de símbolos extremamente abstratos: codificando textos em imagens, fotografias constituem metacódigos de textos. Quando as imagens técnicas são corretamente decifradas, o mundo conceitual surge enquanto seu universo de significado.

$\mathrm{O}$ fato de tratar a imagem fotográfica como algo culturalmente codificado e simbólico, rechaçando tanto a posição indiciária quanto a abordagem icônica, não conduz Flusser, todavia, ao encontro da "segunda abordagem epistemológica" arrolada por Dubois $(2000)^{10}$. Como já vimos, sua visão "pós-histórica" pretende superar justamente qualquer função "ideológica" ou "transformadora" do mundo por parte da imagem. A fotografia não modifica nem interfere nos processos concretos do mundo por ser apenas a revelação particular de uma das inúmeras potencialidades conceitualmente inscritas no programa do aparelho.

A sociedade contemporânea vive cada vez mais em função dessa "magia imagética" que não precede e sim sucede à consciência histórica conceitual e desmagicizante: conhece-se, valoriza-se e age-se em função de tais imagens. Todo ato científico, artístico e político quer ser "fotografado, filmado, videoteipado", ou seja, quer deixar de ser "histórico" para ritualizar um tipo novo de modelo: o programa. "A nova magia é a ritualização de programas, visando a programar receptores para um comportamento mágico adequado.” (FLUSSER, 2002, p.16). Imagens fotográficas nada mais são que conceitos programados monitorando magicamente o comportamento de seus receptores: a consciência histórica e seu modo de pensar conceitual foram substituídos por esta "consciência mágica de segunda ordem”. (FLUSSER, 2002, p.17).

Assim, ao procurar por situações inéditas para clicar, o fotógrafo está na verdade buscando alternativas virtualmente programadas no interior do aparelho, o que torna inadequado perguntar (epistemologicamente) se

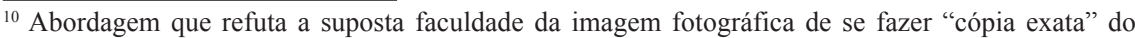
real, já que toda imagem já é uma interpretação ou transformação do real: uma formação cultural, ideológica e codificada.
} 
as situações a serem fotografadas situam-se "lá fora no mundo" ou "cá dentro do aparelho": o gesto fotográfico desmente os realismos e os idealismos tradicionais, já que situações virtuais tornar-se-ão reais assim que se transformarem em imagens técnicas. Inverte-se também o vetor tradicional da significação: o significante (e não o significado ou referente) é a própria realidade - não a existente lá fora, mas a inscrita no aparelho. (FLUSSER, 2002, p.54).

O valor da imagem fotográfica está na informação que ela transmite, pois, enquanto objeto real ou "palpável”, seu valor é evidentemente desprezível, podendo ser reproduzido infinitamente de forma barata e muitas vezes doméstica. (FLUSSER, 2002, p.56). É isto que torna a fotografia o primeiro objeto pós-industrial da história: seu valor transferiu-se do objeto (típico da sociedade capitalista ou socialista) para a informação da sociedade informática. "Na atividade fotográfica, ocorre a desvalorização do objeto em benefício da informação como sede de poder." (FLUSSER, 2002, p.45). Essa informação codificada encontra-se, como já se disse, na superfície do objeto e torna obsoleto o próprio conceito de propriedade: o poder agora está nas mãos de quem programa, não de quem possui. Uma vez decifrado o significado da imagem simbólica, o objeto material pode ser simplesmente descartado; já seu significado pode mudar quantas vezes for preciso: de científico passar a ser político, artístico, privativo etc., em uma incessante operação de transcodificação simbólica. (FLUSSER, 2002, p.45).

Resta dizer que na cultura dominada pela imagem fotográfica não existem mais "analfabetos" ou "iletrados": a supremacia da imagem se deu em detrimento do texto verbal, o que favorece a submissão dos receptores da imagem ao "comportamento ritual" cujo fim é a manutenção de aparelhos. A faculdade crítica dos receptores é reprimida para que a "estupidez absurda do funcionamento do aparelho", a "magia programada", não seja conscientizada. (FLUSSER, 2002, p.70).

Eis, em síntese, o que o livro de Flusser pretende mostrar: por paradoxal que pareça, a civilização das imagens técnicas onipresentes não tornou "mais visível" o conhecimento científico - antes, o falseou; não 
reintroduziu as imagens tradicionais, e sim as substituiu; não denunciou a "magia subliminar" - apenas a trocou por outra. (FLUSSER, 2002, p.18).

\section{Relacionando a teoria de Flusser à AD}

O processo de deciframento da informação simbólica - sub-reptícia, mistificadora e por isso mesmo manipuladora - veiculada pela imagem fotográfica, tal como descrito por Flusser, pode ter na $\mathrm{AD}$ uma metodologia de interpretação auxiliar. Como "as leis do discurso valem também para qualquer outro tipo de enunciação" (MAINGUENEAU, 2011, p.32), é possível estendê-las para o texto imagético fotográfico. Neste sentido, qualquer imagem, mesmo isolada de outro sistema semiótico, pode ser considerada discurso e ser objeto da AD.

Tanto a AD quanto Flussser concordam que: 1) a imagem não é um "ícone" ou "signo icônico", isto é, um analogon da realidade, e sim uma estrutura discursiva e simbólica; 2) a imagem é historicamente codificada; 3) a imagem deve respeitar os mesmos princípios que regem a comunicação em geral ${ }^{11}$. Esses princípios desempenham um papel crucial no processo de compreensão dos discursos porque, por serem préconhecidos pelos interlocutores, permitem a transmissão de conteúdos "implícitos" ou "subentendidos". (MAINGUENEAU, 2011, p.33).

Para a AD, "discurso" é toda linguagem em ação situada em ambientação ou contexto que não "circunda" simplesmente o enunciado, mas determina e especifica seu valor significante. O evento linguísticocomunicacional é sempre um produto cultural empírico entendido como "texto", onde podem ser encontradas as "pistas" ou "marcas" deixadas pelos processos sociais de produção de sentidos que o analista do discurso vai interpretar. (PINTO, 2002, p.26). Nas palavras de Maingueneau (2011,

\footnotetext{
${ }^{11}$ Segundo Maingueneau, para haver comunicação é preciso que se respeite em primeiro lugar o "princípio da cooperação", espécie de "contrato tácito" ou "saber mutuamente conhecido" segundo o qual o destinatário deve supor que o produtor do enunciado respeita determinadas "regras do jogo" e vice-versa. (MAINGUENEAU, 2011, p.32).
} 
p.53): “O discurso é uma organização situada para além da frase”; ele é, acima de tudo, "uma forma de ação".

Situar a imagem fotográfica no ambiente discursivo, ou seja, em um contexto de enunciação pragmática tal como a AD o concebe, é entendê-la não apenas como uma "totalidade coerente", mas, principalmente, como "uma forma de ação sobre o outro e não apenas uma representação do mundo". (MAINGUENEAU, 2011, p.53). Isto porque a $\mathrm{AD}$ não pretende ser uma interpretação semântica de conteúdos; seu interesse não é tanto pelo que o texto "diz" ou "mostra", e sim por como e por que, ao dizer, o texto ou discurso pode ocultar e dissimular. Em outros termos, a $\mathrm{AD}$ trabalha com o sentido não-explícito do discurso: o implícito (não-dito) é um elemento indispensável na construção do significado. Não que haja uma verdade oculta "atrás" do texto a ser alcançada: a AD não está em busca de um hipotético "significado real" dos enunciados, mas das suas diversas possibilidades interpretativas.

O sentido excede, nessa perspectiva, os limites da linguística enquanto ciência abstrata da língua, já que a relação entre as significações de um texto e suas condições socio-históricas é constitutiva das próprias significações. O discurso é parte de uma construção social na qual os limites entre o linguístico e o extralinguístico na verdade não se estabelecem. No plano discursivo, linguagem e sociedade articulam-se intimamente, entremeadas por um contexto pragmático-político (dado que há sempre um embate por poder envolvido) que é um elemento constituinte da própria realidade discursiva. Derruba-se com isso também a noção realista ingênua de que a linguagem é um "meio neutro" de refletir ou descrever o mundo.

No que tange à significação da imagem (ou dos planos nãoverbais de discurso), a AD opõe-se a diversas disciplinas tradicionais da linguística e da semiologia que costumam compreender o não-verbal sempre perpassado pelo verbal. Relativamente ao processo de significação da imagem, as discussões tradicionais estão em geral restritas a duas vertentes principais: ora a imagem é vista como um 
"signo linguístico" entre outros, ora é tratada conforme os elementos (pré-linguísticos) da experiência perceptiva, isto é, segundo fatores tais como a extensão, a distância, a profundidade, a verticalidade, a estabilidade, a cor, a sombra, a textura etc. (SOUZA, 1998). No primeiro caso, ocorre um flagrante reducionismo na própria compreensão de linguagem, encarada única e exclusivamente como uma estrutura gramatical ou verbal. Reduzir a imagem a um signo linguístico significa, dessa forma, não só desprezar os códigos intrínsecos à sua materialidade visual, mas também passar por cima de seus condicionantes históricos próprios. No segundo caso, a relação com o linguístico desaparece completamente em benefício de uma visão eminentemente técnica ou "muda" da imagem: destituída de qualquer caráter textual, a imagem pode apenas ser "descrita" ou "traduzida", ela é um simples dado complementar, um "acessório" ou "cenário" meramente ilustrativo. Ambos os casos, de todo modo, realizam uma descrição meramente formal da imagem que desconsidera a sua dimensão simbólica e historicamente codificada, a diversidade de seus usos, as múltiplas possibilidades de interpretação, seus significados subliminares, em síntese, sua abrangência discursiva (SOUZA, 1998) que é construída "em função de uma finalidade, devendo, supostamente, dirigir-se para algum lugar". (MAINGUENEAU, 2011, p.53).

Nessa medida, embora realçando a não-correlatividade entre a imagem e o discurso verbal, a $\mathrm{AD}$ pretende garantir à imagem a posse de um significado e a capacidade de ser "lida", ainda que esta leitura, ao contrário da leitura sempre unidirecional das palavras, seja necessariamente multidirecionada e dependente do olhar de cada leitor. Mesmo sem conter categorias semânticas e sintáticas precisas tal como o texto verbal, a imagem possui representatividade e referencialidade, $\mathrm{o}$ que corrobora seu status de linguagem e permite entender seus elementos visuais como legítimos operadores de discurso. (SOUZA, 1998). Ressalte-se que isto não ocorre simplesmente porque a imagem também informa ou comunica, e sim porque, em sua especificidade ou materialidade, ela já é um texto ou discurso. 


\section{Considerações finais}

A constituição simbólico-discursiva e historicamente codificada que a $\mathrm{AD}$ atribui à imagem está associada, como facilmente se deduz, a uma dimensão política: um "embate por poder" atua em todo discurso enquanto evento social concreto. Para a AD, de fato, o discurso é sempre um lugar de tensão e conflito - fatores que justamente lhe dão corpo e sentido. O que se passa no discurso multicolorido, espetacular e hipnotizante da "sociedade da imagem fotográfica" descrita por Flusser, é que esse embate por poder não é acompanhado por uma "consciência histórica" nem operado por uma "luta de classes"; seu principal agente é, ao contrário, uma espécie subliminar e programada de magia. Em outras palavras, o sentido do discurso fotográfico perdeu qualquer matiz ideológico, refletindo apenas o comportamento ritualístico, robotizado e manipulado de uma consciência isenta de qualquer faculdade crítica e exclusivamente dedicada ao aperfeiçoamento constante da "sociedade do aparelho". A informação que esse discurso transmite tampouco "representa" o mundo ou afirma algo sobre este; enquanto "texto científico aplicado", não é o mundo, mas determinados conceitos relativos ao mundo que ela veicula. Esse sentido não-explícito do discurso imagético-fotográfico consiste, como vimos, em um elemento indispensável na construção do seu significado.

Na cultura da massificação fotográfica, o discurso corresponde, assim, ao momento em que o emissor emite a informação rumo ao espaço vazio, para ser captada por quem nele se encontra, como no rádio. "[...] O aparelho fotográfico é programado para a distribuição discursiva rumo ao espaço vazio, como o fazem a televisão e o rádio." (FLUSSER, 2002, p.46). Essa discursividade aparentemente difusa, superficial, sem destinatário preciso e quase evanescente constitui a "sede de poder" da sociedade do aparelho. Ela corrobora a magia subliminar do programa enquanto falseia o conhecimento científico que a tornou possível. A imagem fotográfica é, pois, pura forma de ação 
sobre o outro: enquanto conceito programado, sua finalidade é manipular magicamente o comportamento de seus receptores para a manutenção não de uma classe ou segmento social, mas da contínua e indefinida reprodução dos aparelhos.

\section{Referências:}

BARTHES, Roland. Acâmara clara: nota sobre a fotografia. Rio de Janeiro: Nova Fronteira, 1984.

DUBOIS, Philippe. O ato fotográfico e outros ensaios. Campinas: Papirus, 2000.

ECO, Umberto. Tratado geral de semiótica. São Paulo: Perspectiva, 2002.

FLUSSER, Vilém. Filosofia da caixa preta: ensaios para uma futura filosofia da fotografia. Rio de Janeiro: Relume Dumará, 2002.

KRAUSS, Rosalind. O fotográfico. Barcelona: Gustavo Gili, 2010.

MAINGUENEAU, Dominique. Análise de textos de comunicação. São Paulo: Cortez, 2011.

MENEZES, José Eugênio de Oliveira. Para ler Vilém Flusser. Líbero, São Paulo, v.13, n.25, p.19-30, jan./jun. 2010. Disponível em http:// www.casperlibero.edu.br/rep_arquivos/2010/08/02/1280781703.pdf Acesso em: 21 out. 2012.

PINTO, Milton José. Comunicação \& discurso. São Paulo: Hacker Editores, 2002. 
SOUZA, Tania C. Clemente. Discurso e imagem. Perspectivas de análise não verbal. Ciberlegenda, Rio de Janeiro, n.1, 1998.

Disponível em $<$ http://www.uff.br/mestcii/tania1.htm $>$. Acesso em: 10 nov. 2012. 